\title{
MEASURING THE GLOBAL OCEAN SURFACE CIRCULATION WITH SATELLITE AND IN SITU OBSERVATIONS
}

\author{
Kathleen Dohan $^{(1)}$, Fabrice Bonjean ${ }^{(2)}$, Luca Centurioni( ${ }^{(3)}$, Meghan Cronin $^{(4)}$ Gary Lagerloef $^{(1)}$, Dong-Kyu Lee ${ }^{(5)}$, \\ Rick Lumpkin $^{(6)}$, Nikolai A Maximenko ${ }^{(7)}$, Pearn P Niiler ${ }^{(3)}$, Hiroshi Uchida ${ }^{(8)}$ \\ ${ }^{(1)}$ Earth \& Space Research, 2101 Fourth Ave, Suite 1310, Seattle WA, 98212, USA, \\ Email: kdohan@esr.org; lager@esr.org \\ (2) SAT-OCEAN, 53, Boulevard de la Reine, 78000 Versailles, France: Email: fabrice.bonjean@ sat-ocean.com \\ ${ }^{(3)}$ Scripps Institution of Oceanography, UCSD (University of California, San Diego), 9500 Gilman Drive, MC 0213, La \\ Jolla CA, 92093, USA, \\ Email:1centurioni@ucsd.edu; pniiler@ucsd.edu \\ (4) NOAA (National Oceanic and Atmospheric Administration) Pacific Marine Environmental Laboratory, Ocean \\ Climate Research Division, 7600 Sand Point Way NE, Seattle, WA, 98115, USA: Email: Meghan.F.Cronin@noaa.gov \\ ${ }^{(5)}$ Department of Marine Sciences, Pusan National University, Busan, 609-735, Korea, \\ Email: lee@east.ocean.pusan.ac.kr \\ ${ }^{(6)}$ Physical Oceanography Division, NOAA/AOML (National Oceanic and Atmospheric Administration/Atlantic \\ Oceanographic and Meteorological Laboratory), 4301 Rickenbacker Causeway, Miami, FL, 33149, USA, \\ Email:Rick.Lumpkin@noaa.gov \\ (7) International Pacific Research Center, SOEST (School of Ocean and Earth Science and Technology), University of \\ Hawaii, 1680 East West Road, POST Bldg. \#401, Honolulu, Hawaii, 96822, USA, \\ Email: maximenk@hawaii.edu \\ ${ }^{(8)}$ IORGC ((Institute of Observational Research for Global Change), Japan Agency for Marine-Earth Science and \\ Technology, 2-15 NatsushimaCho, Yokosuka, Kanagawa 237-0061, Japan, Email: huchida@jamstec.go.jp
}

\section{INTRODUCTION: GLOBAL OCEAN CIRCULATION}

In the past two decades, the Global Drifter Program (GDP), satellite altimeter missions, precise gravity models and radiometer and scatterometer winds, have provided a detailed resolution of the global sea surface velocity (SSV) and its variability. Out of these has emerged a detailed, unprecedented, description of the surface circulation (calibrated to $15 \mathrm{~m}$ depth), including formerly unknown zonal features and an updated global mean dynamic topography. Using the GDP, along with long time series current meter moorings and numerous ship acoustic Doppler current profiler (ADCP) sections for calibration and validation, we can now resolve the spatial and temporal variability of the global surface currents from satellite sea surface topography and vector wind measurements. This record extends from 1993 to present and provides key dynamical insights into the tropical dynamics of ENSO (El Niño/Southern Oscillation) and extra-tropical variations on intraseasonal to decadal time scales. Beyond the basic oceanographic and climate research applications, the data are useful to marine applications (shipping, fishing, ocean yachting, search and rescue, pollution monitoring, etc.)

This paper describes the state of the observing system, data quality and principal scientific insights during the last decade. The synergy of the satellite and in situ components of this observing system has been essential for resolving the circulation on a global synoptic basis. The future observing system requires at a minimum the continuation of these key components. The OceanObs'99 GDP requirements (one measurement per month per $5 \times 5$ degrees) are reviewed for adequacy to define the mean circulation, seasonal to inter-annual variability, calibrate satellite SSV, resolve eddy kinetic energy, coastal processes, and deploying ancillary sensors for surface salinity and $\mathrm{PCO}_{2}$ (Partial Pressure of Carbon Dioxide).

\section{GLOBAL SURFACE CURRENTS}

This paper describes global surface current observations, with emphasis on the Global Drifter Program sea surface velocity (SSV) and satellitederived SSV. Drifters provide direct measurements of surface velocities, capturing all of the complexity of the currents. Satellite-derived currents offer a consistent regular spatial and temporal coverage, although at too low resolution to measure fine-scale features and at the expense of a sparser time sampling than drifters. The two observations complement each other and together provide continuous high-resolution global SSVs.

\subsection{Drifting Buoy Array}

In concert with numerous partners, NOAA's (National Oceanic and Atmospheric Administration) Global Drifter Program maintains an array of $~ 1250$ satellitetracked surface drifting buoys ("drifters") around the world. These instruments consist of a surface float with satellite (ARGOS) transmitter and thermistor for SST (Sea Surface Temperature), connected by a tether to a holey-sock drogue centered at a depth of $15 \mathrm{~m}$. For a 

Observing System Status: 2009, Q1.
Surface Currents (experimental)

Requirement: $2 \mathrm{~cm} / \mathrm{s}$ accuracy (drogue on); $600 \mathrm{~km}$ resolution; 1 sample per month (GOOS/GCOS, 1999)

Performance measure: reduce the error in global measurement of surface velocity

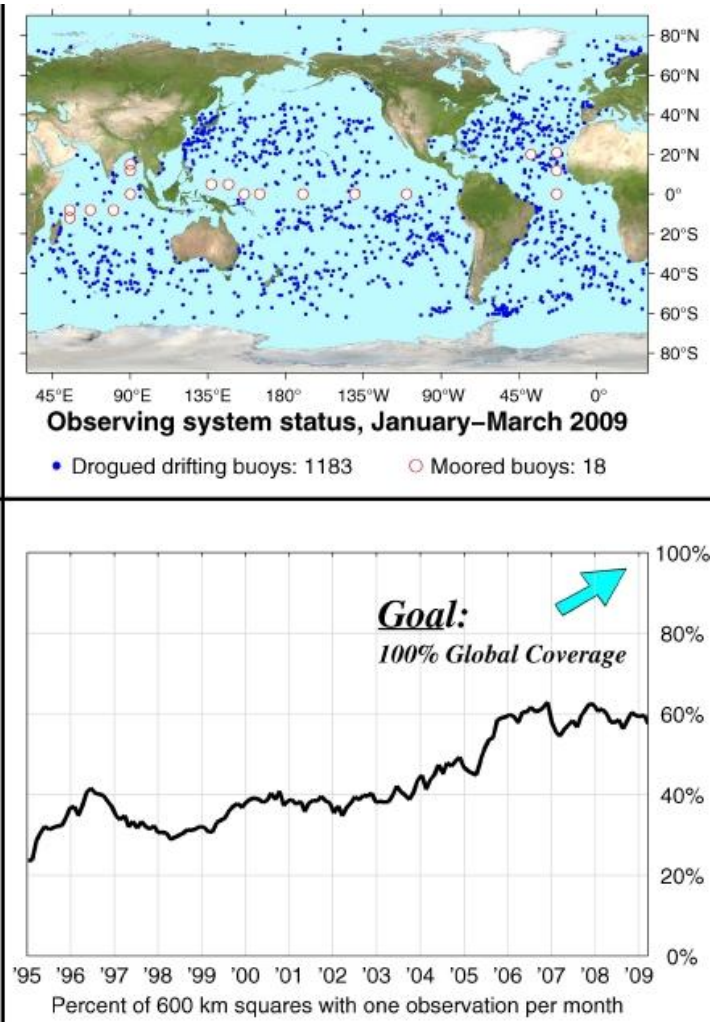

Percent of $600 \mathrm{~km}$ squares with one observation per month

Figure 1. Evaluation of the Global Ocean Observing System for surface current measurements. Top left: GOOS/GCOS requirement. Top right: map of drifting (blue) and moored (white) buoy locations during JanuaryMarch 2009 (latest position of drifters shown). Bottom left: percent of months in January-March 2009 with at least one surface velocity measurement in each $600 \mathrm{~km}$ box. Bottom right: time series of global coverage since January 1995 , showing increase from just over $20 \%$ to current rate of $~ 60 \%$.

history of this instrument's development and deployments in various regions, see [1] and [2]. Drifters dominate the spatial coverage of surface velocity measurements in the Global Ocean Observing System (GOOS). Raw drifter positions are distributed in real time on the GTS (Global Telecommunication System), and in delayed mode with quality control, interpolated to regular six-hour intervals, by NOAA's drifter Data Assembly Center (DAC; http://www.aoml.noaa.gov/phod/dac). Since January 2005 raw satellite position fixes for each drifter are collected at a mean temporal resolution of 1.2 hours globally, allowing the resolution of semidiurnal tides, inertial oscillations and superinertial waves [3].

The GOOS (OceanObs'99) requirement for current measurements is one measurement per month, per 600 $\mathrm{km}$ box, with an accuracy of $2 \mathrm{~cm} / \mathrm{s}$. The spatial resolution of this requirement comes from the SST requirement to reduce satellite SST bias, and does not conform to autocorrelation scales for velocity measurements. The present network of moored and drogued drifting buoys meets this requirement over $60 \%$ of the ocean (Fig. 1), with much of the remaining undersampled regions confined to the partially ice-covered Southern Ocean, regions of strong surface divergence that are not populated with moored buoys, and relatively shallow regions such as the Indonesian Seas.

The data management system for drifting buoys, and recommendations for the future, are given in [4].

\subsubsection{Complementary In-Situ Measurements}

In addition to drifting buoys, surface current information is measured through moored current meters, shipboard ADCPs (Acoustic Doppler Current Profilers), XBT (Expendable Bathythermograph) transects, gliders, and Argo floats.

Moored current meters are an integral part of the global tropical array of ATLAS-type (Autonomous Temperature Line Acquisition System) buoys [5], of extratropical moorings such as the Stratus mooring $\left(20^{\circ} \mathrm{S}, 85^{\circ} \mathrm{W}\right)$, Kuroshio Extension Observatory $\left(32^{\circ} \mathrm{N}, 145^{\circ} \mathrm{E}\right)$ and Ocean Station Papa $\left(50^{\circ} \mathrm{N}, 145^{\circ} \mathrm{W}\right)$, and other sites within the OceanSITES (OCEAN Sustained Interdisciplinary Time series Environment observation System) network [6]. Many of these moorings include point acoustic meters at $10 \mathrm{~m}$ depth for 
near surface currents, and some include additional meters to measure vertical shear. Data from the moored tropical array is quality controlled and distributed by the Tropical Atmosphere Ocean project (http://tao.noaa.gov/).

Although measuring surface velocity is not the primary mission of Argo floats, they typically spend 6-24 hours at the surface transmitting data to passing satellites. During this time, their position fixes can be used to infer surface velocity [7] and [8], albeit with less accuracy than drifters because they are not drogued and are thus more susceptible to wind and wave action.

Autonomous gliders may sometimes be the only in situ measurement device available, for example under sea ice [9]. Other sources of in situ data come from instrumented ships of opportunity that perform XBT transect sampling and ADCP measurements complementary to the Argo sampling ([10] and [11], and http://ilikai.soest.hawaii.edu/sadcp/).

\subsection{Satellite Derived Surface Currents}

Ocean Surface Current Analysis Real-time (OSCAR, [12] Mercator/SURCOUF, and the Centre de Topographie [13] des Océans et de l'Hydrosphère (CTOH, [14]) provide global surface current products directly calculated from satellite altimetry and ocean vector winds.

The OSCAR data processing system calculates SSV from satellite altimetry (AVISO (Archiving, Validation and Interpretation of Satellite Oceanographic data)), vector wind fields (QuikSCAT), as well as from sea surface temperature (Reynolds-Smith) using quasi-steady geostrophic, local wind-driven, and thermal dynamics. Near real-time velocities are calculated on both a $1^{\circ} \times 1^{\circ}$ and $1 / 3^{\circ} \times 1 / 3^{\circ}$ grid on a $\sim 5$ day timebase over the global ocean. Surface currents are provided on the OSCAR website (http://www.oscar.noaa.gov) starting from 1992 along with validations with drifters and moorings. The $1 / 3^{\circ}$ resolution is available for $\mathrm{ftp}$ download through ftp://ftp.esr.org/pub/datasets/SfcCurrents/ThirdDegree.

SURCOUF and the $\mathrm{CTOH}$ currents are available respectively from http://www.mercatorocean.fr/html/science/piste_rouge/syst_ops/surcouf_en. html, and http://www.legos.obsmip.fr/soa/altimetrie/ctoh/SURF_CUR/. altimetry-based surface current products are also available, for example, the AVISO, CSIRO (Commonwealth Scientific and Industrial Research Organisation), and CCAR (Colorado Center for Astrodynamics Research) surface currents.

Satellite surface current products are routinely validated with in situ data: globally with surface drifters and regionally with mooring and shipboard ADCP. Moorings provide time series at a stationary location, in contrast to Lagrangian drifter data, and are particularly useful in equatorial divergent zones. However, a finer than 2 degree spacing in latitude for moorings would help resolve important wave dynamics such as tropical instability waves or the location of the equatorial zonal jets, both of which are sensitive to the turbulence parameterizations used in the wind-driven OSCAR calculations.

\subsection{Global Circulation Maps}

The general structure of the global surface circulation as observed from drifters and from satellite currents is provided in Fig. 2 [64]. The figure highlights the differences in surface circulation maps when derived from drifter-ensemble averaged velocities or from a sum of time averaged geostrophic and Ekman currents (simple model).

\section{PROGRESS}

\subsection{Scientific Advances Using SSV}

Drifters are invaluable as a validation tool for models and satellite-derived currents. Because drifters measure total currents, including the wind-driven Ekman component, their data can be used to test parameterizations of wind-driven upper ocean motion [15]. Drifter data can also be synthesized with altimetry and satellite winds to estimate absolute sea height ([16] and [17]).

Satellite surface currents have been used to understand the role of surface transports in the genesis of the 1997/98 El Nino [18], and the 2002/03 El Nino ([19] and [20]). Monthly OSCAR maps and anomalies are used routinely to monitor ENSO and to test prediction models (Climate Diagnostic Bulletin, Climate Prediction Center and NOAA). The first empirical orthogonal function (EOF) of the surface current anomalies, used as an ENSO index, leads the sea surface temperature EOF index by weeks to months.

In addition to the ENSO-related investigations, the OSCAR analyses have been used in a wide range of studies, such as the role of salt transport in tropical freshwater [21], the influence of tropical instability waves on phytoplankton blooms in the Pacific ([22] and [23]), and the mixed-layer temperature balance [24]. In the tropical Atlantic, studies have addressed equatorial divergence and upwelling dynamics [25], interannual equatorial long waves [26] and the mixed-layer salinity balance [27]. The surface current field was also used to assess the seasonal cycle of diabatic heat storage in subregions of the Pacific [28] and in surface heat flux estimates ([29] and [30]); the spatial and temporal context of the seasonal-to-interannual timescale currents was examined in order to study intraseasonal variability and dynamics in the tropics ([31] and [32]). The data are also in use for fishery resource management research, 
marine animal migrations studies and other maritime applications throughout the tropical Pacific. OSCAR SSV has been used to assess the surface current field from the oceanic data assimilation systems of NCEP and ECMWF (The European Centre for Medium-Range Weather Forecasts) ([33 and [34]). The Griffies CWP [35] addresses the role satellite and in situ observations play in large-scale circulation models.

\subsection{Multiple Data Sources}

\subsubsection{Combined Drifter and Satellite Observations}

Drifters are a useful as an independent validation tool for satellite currents. Scientific advances can also be made when drifter data are synthesized with altimetry and satellite winds, for example to estimate absolute sea height ([16] and [17]).

\subsubsection{Daily current maps in the East/Japan Sea}

In the East/Japan Sea, daily near real-time surface current map are produced by the National are provided to the public through the website (http://mdc.nori.go.kr/current/Myweb/nori/recent.pdf

Fig. 3). Daily velocities are calculated from unbiased mean geostrophic current added to the geostrophic current from merged sea level anomaly (ftp.cls.fr) and near real-time observation from drifters. Adding unbiased mean geostrophic current to the estimated current from merged satellite altimetry improves correlation between observed current by drifters and estimated current from 0.56 to 0.77 and it shows marked improvement on detection of eddies especially in the coastal area. Near real-time current maps have been successfully used by Korean Coast Guard for several instances and Navy, merchant ships and fishing boats are also heavy users of the daily current maps.

\subsubsection{Monitoring of the Kuroshio Flow}

By combining anomalies (i.e., deviations from the mean) of sea-surface geostrophic velocity obtained from altimeter data and in situ surface velocities estimated from trajectories of surface drifters, unbiased temporal mean geostrophic velocity field can be accurately estimated [37]. The method is applied to the surface flow field of the North Pacific, and the obtained mean velocity field clearly shows the Kuroshio and Kuroshio Extension, which are narrower and stronger than the climatological mean feature derived from historical hydrographic data averaged over several decades [38].

Instantaneous velocities can be estimated by summing up these temporal mean velocities and anomalies derived from altimeter data. By tracking the locally strongest part of the velocity field, the Kuroshio axis can be extracted [39]. It is well known that the Kuroshio path south of Japan can be categorized into two typical patterns: the Non Large Meander (NLM) path and the
Large Meander (LM) path. In 2004, the Kuroshio shifted from the NLM path to the LM path for the first time after the TOPEX/Poseidon (T/P) altimetry started in October 1992. Therefore, the transient processes leading to the LM path of the Kuroshio can be examined in detail (Fig. 4 and [40]). The observed features are well reproduced in the model results by Endoh and Hibiya [41], who demonstrated the important role of baroclinic instability over Koshu Seamount in the formation of the LM path of the Kuroshio.

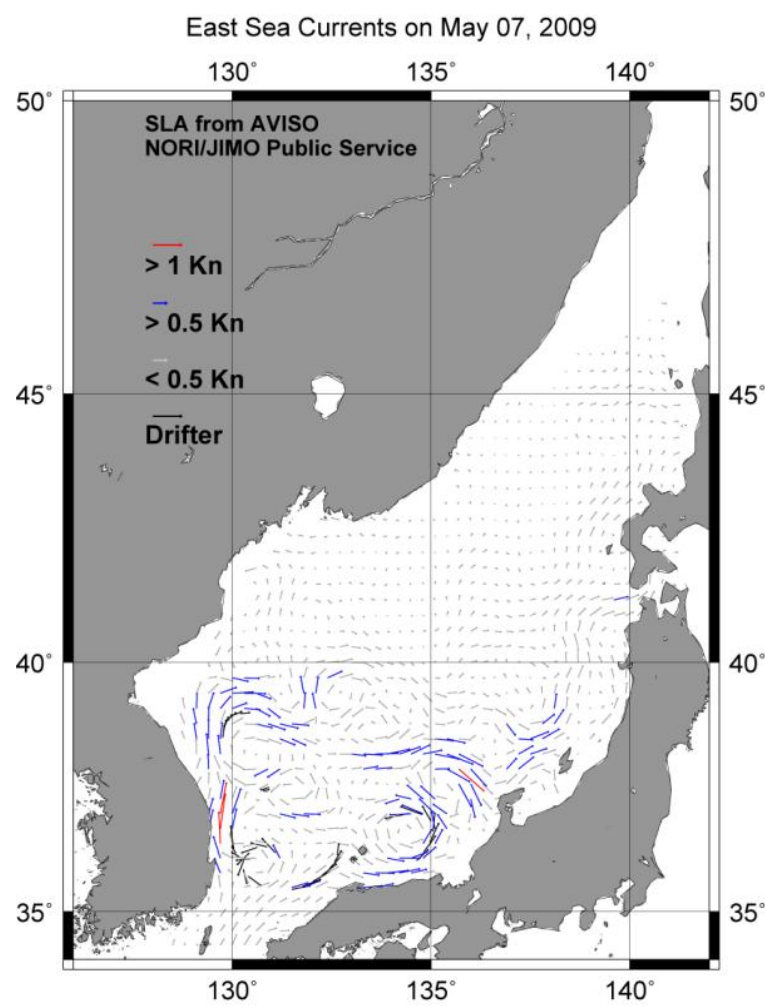

Figure 3. Daily current map produced by NORI (http://mdc.nori.go.kr/current/Myweb/nori/recent.pdf).

\subsubsection{Multiple Satellites}

High spatial resolution is important in detecting features at oceanic fronts, in coastal areas, and to detect new features, such as striations, jets, stationary Rossby waves, and eddies. The AVISO Ssalto/Duacs (Segment Sol multi mission d'Altimétrie, d'Orbitographie et de localisation précise/Developing Use of Altimetry for Climate Studies) multi-mission altimeter products incorporate observations from several satellites (Jason1\&2, T/P , ENVISAT (Environmental Satellite), GFO (GEOSAT (Geodetic \& Oceanographic SATellite) Follow-On), ERS-1 \& 2 (European Remote-Sensing Satellite), and Geosat) in order to provide the highest resolution, most consistent SSH (Sea Surface Height) data possible. As the number of satellites increases, so does the SSH resolution.

The scale of structures resolved by $1 / 3^{\circ}$ OSCAR is 


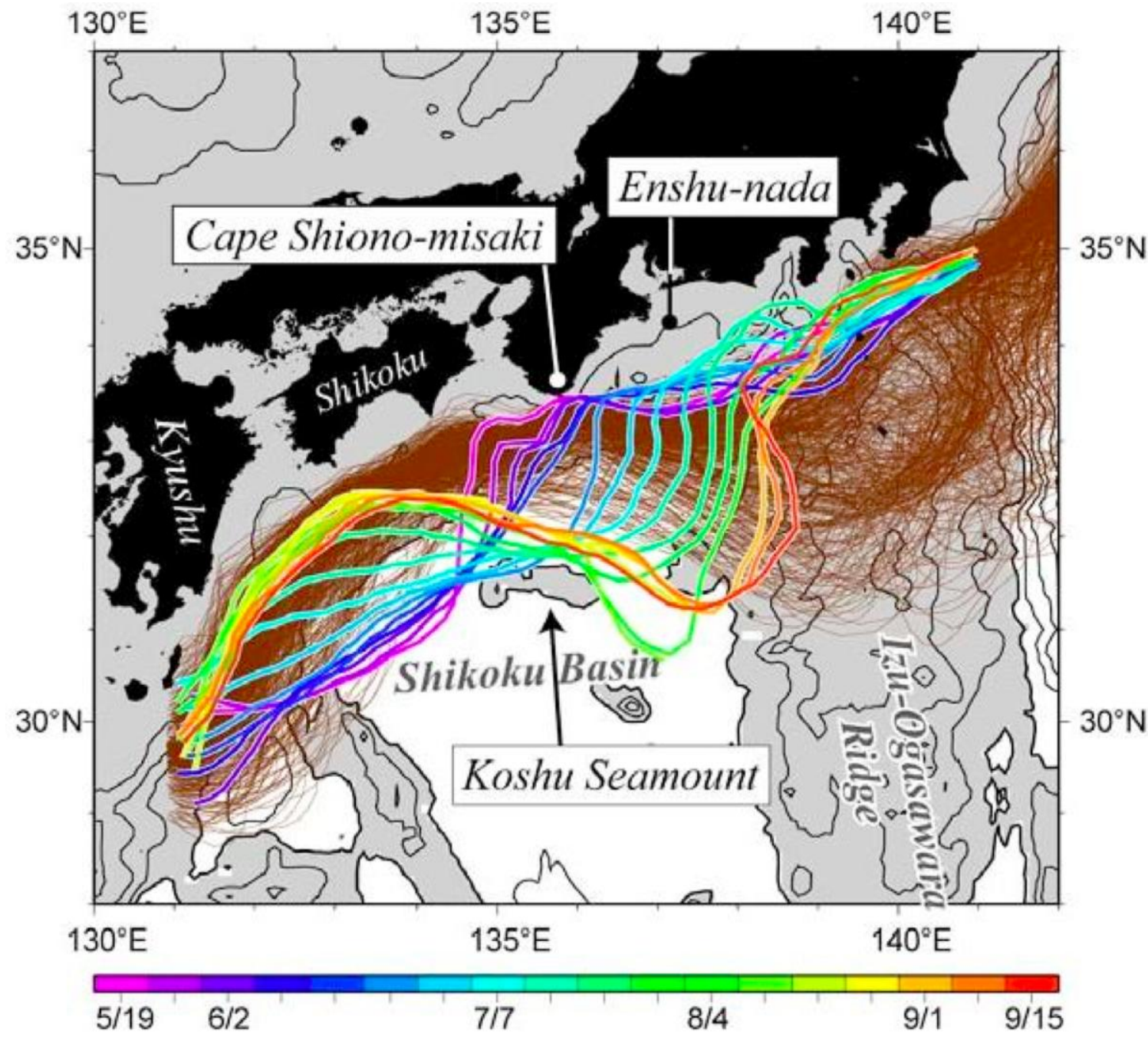

Figure 4: Location of the Kuroshio axis every 7 days, from May 19 to September 15 in 2004, (thick color lines) and, from 1993 to 2003, (thin brown lines), superposed on the bottom topography (contour interval is $1000 \mathrm{~m}$ ). Areas with the depth shallower than $4000 \mathrm{~m}$ are shaded. From [40].

shown in the sample region of the Gulf Stream in the top plot of Fig. 5. In addition to OSCAR velocities, drifter tracks in the surrounding months are over plotted. The figure shows the contrast between the spatial coverage obtained with satellite data against the drifter high temporal resolution with its ability to capture the fine-scale details.

The bottom plots of Fig. 5 show the increase in performance of OSCAR as the resolution is increased from $1^{\circ}$ to $1 / 3^{\circ}$. OSCAR velocities are mapped to daily averaged drifter locations (the vector plots), and statistics are calculated between the two data sets, visualized by the scatter plots of zonal and meridional velocities [42]. Not only do correlations and variances improve with the increased resolution, but the magnitudes of the velocities also better match the drifters. Since geostrophic velocities are calculated from $\mathrm{SSH}$ gradients, as the SSH grid resolution increases, the gradients are sharpened and the accuracy of the SSV calculation increases. Additional descriptions and scientific advances from using multiple satellites and multiple observational data as well as limitations connected with the various satellite data sets are described in the Scott CWP [43]

\subsubsection{Multi-platform Observing Systems}

A strong appreciation for the necessity of a combined ocean observing system to study the global surface circulation in conjunction with regional intensive observing systems is echoed in many of the CWPs in the OceanObs'09 collection. 


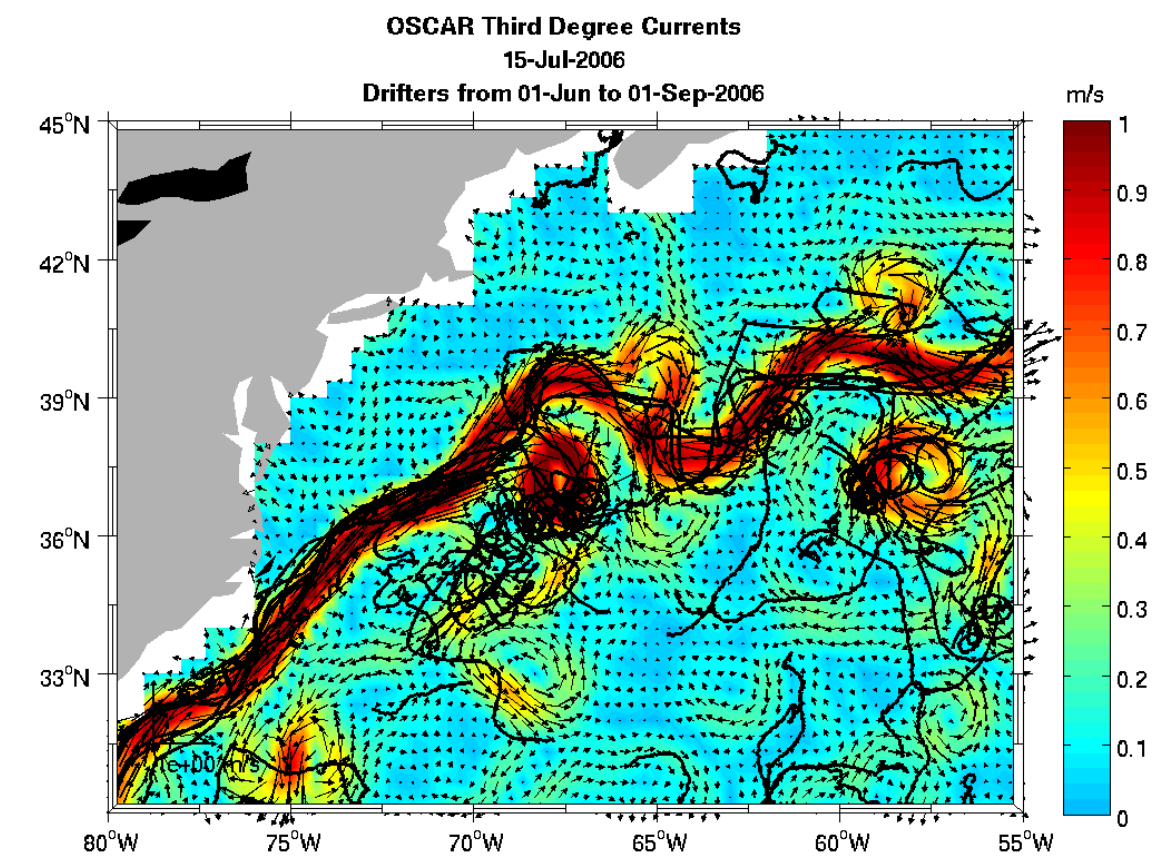

OSCAR1deg \& DRIFTER DATA: Jun.01,2006-Sep.01,2006 Background field: OSCAR1deg monthly mean
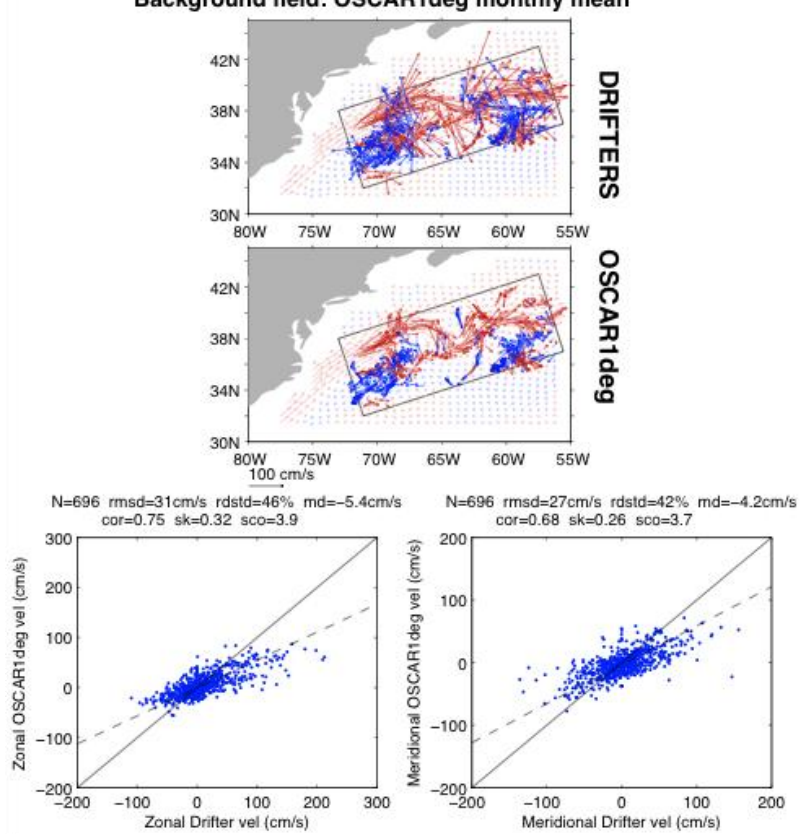

OSCARthirddeg \& DRIFTER DATA: Jun.01,2006-Sep.01,2006 Background field: OSCARthirddeg monthly mean
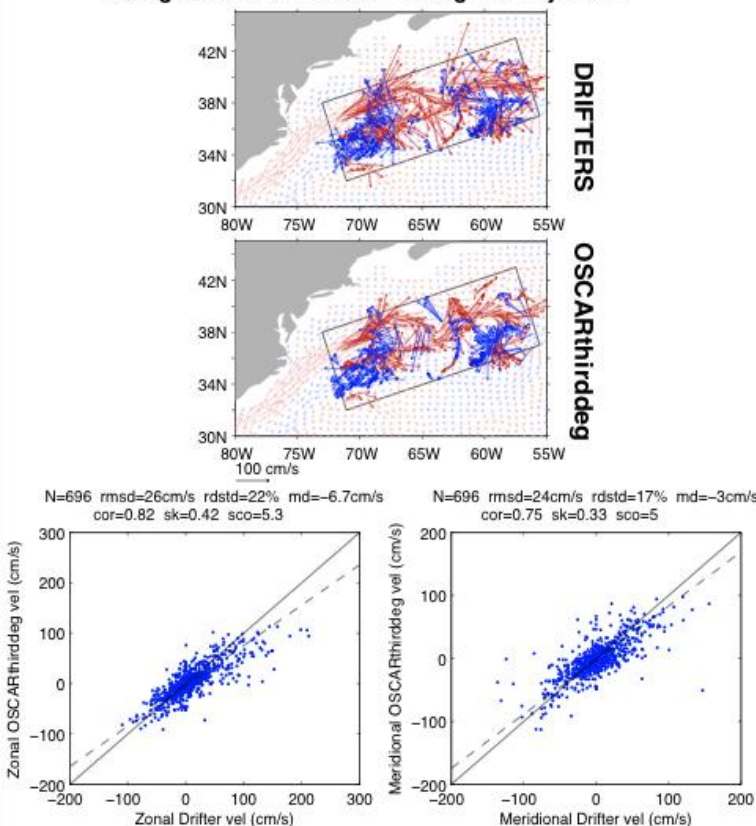

Figure 5. Top: Sample OSCAR velocity field in the Gulf Stream demonstrating the scale of the structures in the velocity field. Drifters tracks are including in the months surrounding the plotted day. Bottom: Drifter comparison studies for OSCAR 1-degree (left) and OSCAR 1/3-degree (right). OSCAR velocities are mapped to drifter locations during Jun 01-Sep 01, 2006. Scatter plots of OSCAR versus drifter velocities are provided for zonal and meridional components. Solid lines are the 1-1 lines, dashed the best-fit through the data. 
An example of the application and benefits of the synthesis of the various ocean observations is the IndOOS (Indian Ocean Observing System)observing system which incorporates data from Argo floats, surface drifting buoys, tide gauges, a surface mooring buoy array, VOS based XBT/XCTD (eXpendable Conductivity, Temperature, and Dept) sections, and satellite measurements. See the Masumoto CWP [44] for a detailed description of the system, as well for seeding problems with drifters in strong wind regions. The combined data allow for studies from forecasting through to decadal climate studies. They emphasize the benefits of an integrated system of in situ and remotely sensed data from both regional and basin-scale observing systems, together with data assimilation models.

More examples of integrated observing systems are described in the Gordon [45] CWP on interocean exchange. Moorings, pressure gauges, high frequency radar, XBT and XCTD sections, inverted echo sounders, drifters, Argo profilers, gliders, instrumented ships of opportunity and satellite observations are all used. In addition, a mooring array (ACT (Agulhas Current Timeseries) will be positioned following a Jason track with the intention of optimally combining observational data. These can validate numerical simulations and be used in data assimilations for a complete picture of the role of Agulhas eddy leakage for the MOC (Meridional Overturning Circulation).

The Lee [46] and Stammer [47] CWPs describe the methods of synthesis of available ocean observations, such as in the observing systems above, with the dynamics of ocean general circulation models in order to generate an estimate of the ocean state.

\section{INDIRECT APPLICATIONS}

There are numerous direct uses of SSV, such as for navigation and drift trajectories, advection calculations of ocean properties, spills, and SAR (Synthetic Aperture Radar) operations, etc. However, SSV can also be used indirectly in determining wind stress and bulk air-sea fluxes. In the Fairall et al. (2003) COARE (Coupled Ocean-Atmosphere Response Experiment) bulk algorithm [48], the wind stress and heat fluxes depend upon wind relative to surface flow. In regions of strong currents, a significant error can result. For example in the eastern tropical Pacific Cronin et al. [49] found that a $1 \mathrm{~m} / \mathrm{s}$ error in the relative winds (due for example by not accounting for a $1 \mathrm{~m} / \mathrm{s}$ ocean current) could cause a $14 \mathrm{~W} / \mathrm{m} 2$ error in latent heat loss. Consequently, Cronin et al. recommends using the OSCAR product to reference the winds in bulk flux calculations if direct measurements are not available. Similarly, the ocean surface current product could be used to reference the scatterometer wind measurements (which measure wind stress) to the fixed earth.

\section{DATA MANAGEMENT AND ANALYSIS}

Data management must remain continual and consistent for a reliable climate record. The error estimates for data sets must be clearly available to users.

Some open scientific questions can be addressed with targeted analysis of existing Lagrangian, Eulerian, in situ and satellite observations. The ocean is heterogeneous, where no universal method of satellite data retrieval for surface currents can be shown to apply. The sea level mapping function used for altimetry data could be re-examined for optimization for longitude, latitude region and time lag, with the best-fit models derived in conjunction with drifter data. Coastal observing systems can be combined with the satellite observing systems to continuously extend SSV to the coast. Resources need to be devoted towards developing methods of treating the surface drifter data, to access the rich structure contained within the fields beyond mean field, eddy kinetic energy, and diffusion calculations towards more dynamically complex calculations such as eddy transport, wave dynamics and time-variability.

\section{FURTHER OBSERVATIONS FOR A HETEROGENEOUS OCEAN}

The ability to calculate SSV from SHA (Secure Hash Algorithm) varies in performance across dynamical regions of the ocean: subtropical gyres, western and eastern boundary currents, equatorial systems, the Antarctic circumpolar flow (ACC), and marginal seas. Agreement between OSCAR and drifter velocities is best in strong flows, either in strongly geostrophic flows or in strong wind conditions. Correlations with drifter SSVs range from over 0.8 in boundary currents and the zonal component of equatorial velocities, down to 0.5 in open gyres. The discrepancies between drifter and OSCAR SSV are due to low spatial resolution, low temporal resolution (in particular for the wind component), errors involved in mapping OSCAR to drifter locations, the gridding method in the AVISO fields (see [43]), missing dynamics in the satellite calculations (such as quasi-steady, linear), and too high signal-to-noise ratio for the weak currents. Multiobservational campaigns in strategic locations are necessary to fill the gaps in knowledge of the surface circulation and its connection to vertical processes.

\subsection{Boundary Currents}

Boundary currents play a key role in ocean circulation, however the scale of boundary currents are often small enough $(<100 \mathrm{~km})$ to be smoothed by altimeters and inadequately sampled by drifters. To fully capture the 
variability in momentum and vorticity, the vertical profile of the currents, and the turbulent fluctuations would require extensive long-term high-resolution sampling with multiple instruments (See: Send CWP [50] and Cronin CWP [51]). In addition, the strong temperature fronts associated with boundary currents interact back with the wind field [52], requiring high resolution temperature SST measurements for a full understanding of the currents.

\subsection{Mesoscale and Sub-Mesoscale}

Much of the vertical exchange of energy and nutrients in the upper ocean is controlled by processes at the submesoscale. In situ velocity observations have proven to be useful in estimating the mesoscale structure of the ocean circulation. Correlation between satellite altimetry and drifter observations is low in the upwelling regions of the eastern boundary currents. Energetic filaments and eddies are common in these regions and the time/space scales of the flow are too fast/small to be resolved by the altimeters. In both eastern and western boundary currents, the coordinated use of long range HF (High Frequency) radars and drifter observations are needed to improve our knowledge of the dynamical processes that drive the circulation. The societal applications are significant since some of the most important fishing grounds of the world are along the American and African continents.

The planned Surface Water and Ocean Topography (SWOT) mission will provide an unprecedented global characterization of fine-scale filaments and fronts, with $\mathrm{O}(10 \mathrm{~km})$ resolution, with a larger range for coastal altimetry. The Fu CWP [54] has a detailed description of the SWOT mission. The improved gravity model from the GOCE satellite will provide high-resolution dynamic topography that can be compared with the velocity data.

\subsection{Fast Timescales}

The 7-day time-base altimetric products are useful for most geostrophic calculations, but faster time-scales are needed to capture the ageostrophic components. It is the ageostrophic velocity that contains the greater part of the divergence, not the geostrophic velocity, bringing up water for carbon dioxide exchange and nutrients. The western boundary currents have variations on time scales of 1-4 days that cannot be sampled by the altimeter systems today.

Drifters now have high enough temporal resolution to capture inertial motions but do not have the spatial resolution of satellites. In order to capture and quantify the wind-driven energy input into the open ocean it is necessary to capture near inertial oscillations (NIO). The inertial peak is the main energy source in the mixed layer. Propagation of NIO out of the mixed layer into the deep ocean is a key source of internal wave energy, comparable to the energy from internal tides ([55] and MacKinnon CWP [56]). The drifter field provides a map of the global eddy field and decay rates but a global census of near-inertial energy observed by drifters [57] has revealed significant discrepancies with the latest mixed layer models. A higher temporal satellite wind field would close the information gap for surface wind forcing and provide the missing step to wind-energy input into the deep ocean.

\subsection{Vertical Structure}

The definition of 'surface' circulation needs to be reexamined as the measurements become more extensive and the applications more complicated. For example, OSCAR currents are calculated as average currents in the upper $30 \mathrm{~m}$, with the vertical structure implicitly defined within the model. Vertical structure/shear occurs not only in Ekman currents of full complexity, but includes all high-frequency motions that rectify into the currents that are sensed with the tools that commonly integrate the signal in time (i.e., drifters) and/or in space (i.e., satellites). Definitions of 'surface current' and 'sea surface' itself are vague under rough weather conditions. Vertical shear of horizontal velocity is important to adequately describe trajectories of different kinds of marine debris and pollutants (oil, plastic, 'ghost' nets, etc.), and different kinds of plankton that move between different depths during their life cycles. This will also help to better understand vertical momentum fluxes in the mixed layer and across the airsea interface.

\subsection{Drifter Slip}

Drifters are susceptible to slip, defined as motion with respect to the water at $15 \mathrm{~m}$ depth, caused by direct wind forcing, drag induced by wind-driven shear, and surface wave rectification [58]. In $10 \mathrm{~m} / \mathrm{s}$ wind, a drifter's slip has been measured at $0.7 \mathrm{~cm} / \mathrm{s}$ [59]. However, the slip at wind speeds exceeding $10 \mathrm{~m} / \mathrm{s}$ and the related wave conditions has not been measured. Wave climatology maps show regions of significant wave height, in excess of 4-5 m, in the ACC region during Austral winter as well as areas in the N. Atlantic and N. Pacific during boreal winter. New measurements are needed to better understand how drifters behave when the wave's height is a considerable fraction of the drogue's depth. Other factors besides slip may also be critical to assess drifter measurements in high wind states, such as inhomogeneous sampling of lateral velocity variations due to the development of Langmuir-type structures [60].

\subsection{Coastal Regions}

Satellite altimetry is limited close to coasts due to problems such as land contamination of the waveform, wet tropospheric delay, and tidal aliasing. However, coastal regions are of importance for small-crafts, 
biology, land pollutants, river exchange, and coastal current systems. Coastal observations, such as moorings, HF radar, and in situ wind measurements, need to be connected to outside satellite calculations. There is promising research towards overcoming some of the contamination issues, extending altimetry closer to the coasts and bridging the gap between open ocean altimetric currents and in situ observations (see the Cipollini CWP [61. The SWOT mission will bridge the gap further, by bringing altimetry closers to the coasts.

\subsection{Salinity}

The launch of the SMOS (Sea and Land Surface Temperature Radiometer) and Aquarius/SAC-D ((Scientific Application Satellite-D sea surface salinity measuring satellites in the fall of 2009 and 2010, respectively, when combined with SSV observations, will bring new insights into basin-scale transport (Lagerloef CWP [62]).

\section{OCEAN OBS '09 RECOMMENDATIONS}

\subsection{Crucial: Sustained Satellite Constellation and Drifter Program}

It is crucial to sustain the existing observation network of satellite altimetry, drifters, and scatterometer winds, and to sustain the high level of data management for each. It is crucial for the climate record for these data sets to remain continuous.

\subsection{Synergy of Observing Systems}

Understanding the global circulation requires an understanding of the global surface circulation and its connection to key regional systems. In order to make accurate transport estimates, and to relate surface processes to interior processes, surface and subsurface current measurements are required in each region using multiple types of observations which are catered to the local dynamics and multi-scale variability (fine-scale, fast time scale, vertical processes).

\subsection{Error Analysis}

The errors and limitations for each observational data set and data product need to be made transparent to the users. For example, slip may potentially introduce a strong ageostrophic component to drifter velocities at high wind and wave states. For these data to be of maximum value, it is crucial that these processes be quantified in future studies.

\subsection{Proposed Further Instrumentation for Global Circulation}

\subsubsection{SWOT}

The SWOT wide-swath interferometric altimeter will capture in a global sense the sub-mesoscales and be able to measure much closer to the coasts. It is not recommended as a replacement for the Jason-class altimeters, but as an addition.

\subsubsection{Scatterometers}

A constellation of scatterometer satellites, to provide vector winds on an approximately 6-hour time resolution is necessary to close the information gap on wind-driven energy input into the interior ocean. This possibly may be attained by working internationally to share scatterometry data.

\subsubsection{Extra sensors on moorings, drifters, and floats}

Reference station moorings should measure currents at the standard depth of $15 \mathrm{~m}$. Outfitting drifters and floats with extra sensors, such as 3-D accelerometers and salinity, SLP (Sea Level Pressure ) and PCO2 sensors [63], will help in understanding the next level of complexity in the surface circulation, in particular the vertical processes controlling the basin-scale surface advection.

\section{SUMMARY}

From satellite-derived analyses, the global velocity field is highly resolved to the mesoscale on $\sim 5$ day Eulerian timescale, with calibration and verification from drifters. Meanwhile, the global array of $\sim 1250$ drifters, as a stand-alone system, resolves the climatology and reveals interesting new features of the mean circulation (e.g. [64]). Both approaches to surface velocity calculations are necessary to provide both the consistent spatial coverage (satellite) and the fine-scale temporal coverage (in situ).

The OceanObs'99 requirement of one SSV measurement per month per $5 \times 5$ degrees is inadequate for any surface circulation calculation beyond climatology. A synthesized in-situ and remote observing system for SSV must resolve surface current variations at the mesoscale (e.g. [65]) in the open ocean. Furthermore, as more measurements are accrued, the relevance of the fine-scale structure, ageostrophic components, and vertical near-surface shear is emerging. The global observing system is evolving as we learn to make computations from our observations. Because of the short time-scales and fine space-scales, either a different approach or new altimeters are needed for the boundary currents and the upwelling systems. One approach would be to release a larger fraction of drifters in boundary currents and let existing satellites and winds be used to compute the currents in low eddy activity regions. A finer spacing than 2 degrees for the equatorial moorings is necessary to resolve the structure of the equatorial zonal jets and instability waves, both because of the spatial structure of these features and the higher errors associated with SSH-based velocity estimates near the equator. Higher frequency and spatial resolution winds will be crucial in improving SSV measurements in open basins and closer to coasts, at 
which point the high frequencies in the drifter data information will be fully exploited.

\section{REFERENCES}

1. Niiler, P. (2001). "The world ocean surface circulation" in Ocean Circulation and Climate-Observing and Modeling the Global Ocean. Edited by J. Church, G. Siedler, and J. Gould. Academic Press, San Diego, 193204.

2. Lumpkin, R. and Pazos, M. (2007). "Measuring surface currents with Surface Velocity Program drifters: the instrument, its data, and some recent results". Chapter two of Lagrangian Analysis and Prediction of Coastal and Ocean Dynamics (LAPCOD). ed. A. Griffa, A.D. Kirwan, A.J. Mariano, T. Ozgokmen and T. Rossby, Cambridge University Press.

3. Elipot, S. and Lumpkin, R. (2008). Spectral description of oceanic near-surface variability, Geophys. Res. Lett. 35 L05606, doi:10.1029/2007GL032874.

4. Keeley, R., Pazos, M. and Bradshaw, B., (2010). "Data Management System for Surface Drifters" in these proceedings (Vol. 2), doi:10.5270/OceanObs09.cwp.47

5. McPhaden, M. \& Co-Authors (2010). "The Global Tropical Moored Buoy Array" in these proceedings (Vol. 2), doi:10.5270/OceanObs09.cwp.61

6. Send, U. \& Co-Authors (2010). "OceanSITES" in these proceedings (Vol. 2), doi:10.5270/OceanObs09.cwp.79

7. Park, J.J., Kim, K., King, B.A. and Riser, S.C. (2005). An advanced method to estimate deep currents from profiling floats. J. Atmos. Oceanic Technol. 22(8), 12941304

8. Lebedev, K., Yoshinari, H., Maximenko, N.A. and Hacker, P.W. (2007). YoMaHa'07: Velocity data assessed from trajectories of Argo floats at parking level and at the sea surface, IPRC Tech. Note 4.2, 16pp.

9. Lee, C. \& Co-Authors (2010). “Autonomous Platforms in the Arctic Observing Network" in these proceedings (Vol. 2), doi:10.5270/OceanObs09.cwp.54

10. Goni, G. \& Co-Authors (2010). “The Ship Of Opportunity Program" in these proceedings (Vol. 2), doi:10.5270/OceanObs09.cwp.35

11. Hood, M. \& Co-Authors (2010). "Ship-Based Repeat Hydrography: A Strategy for a Sustained Global Program." in these proceedings (Vol. 2), doi:10.5270/OceanObs09.cwp.44

12. Bonjean, F. and Lagerloef, G.S.E. (2002). Diagnostic Model and Analysis of the Surface Currents in the Tropical Pacific Ocean. J. Phys. Oceanogr. 32, $2938-$ 2954.

13. Larnicol, G., Guinehut, S., Rio, M.-H., Drevillon, M., Faugere, Y. and Nicolas, G. (2006). The Global Observed Ocean Products of the French Mercator project, Proceedings of 15 Years of progress in Radar Altimetry Symposium, ESA Special Publication, SP-614.
14. Sudre J. and Morrow, R. (2008). Global surface currents: A high resolution product for investigating ocean dynamics, Ocean Dyn. 58(2) 101-118.

15. Elipot, S. and Gille, S.T. (2009). Ekman layers in the Southern Ocean: spectral models and observations, vertical viscosity and boundary layer depth, Ocean Sci. 5 115-139.

16. Niiler, P.P., Maximenko, N.A. and McWilliams, J.C. (2003). "Dynamically balanced absolute sea level of the global ocean derived from near-surface velocity observations”. Geophys. Res. Lett. 30(22), 2164-2167.

17. Rio, M.H. and Hernandez, F. (2003). "High-frequency response of wind-driven currents measured by drifting buoys and altimetry over the world ocean." J. Geophys. Res.-Oceans 108(C8) 3283-3301.

18. Picaut, J., Hackert, E., Busalacchi, A.J., Murtugudde, R. and Lagerloef, G.S.E. (2002). Mechanisms of the 1997 1998 El Nino-La Nina, as inferred from space-based observations. J. Geophys. Res. 107(C5): doi:10.1029/2001JC000850.

19. Lagerloef, G.S.E., Lukas, R., Bonjean, F., Gunn, J.T., Mitchum, G.T., Bourassa, M. and Busalacchi, A.J. (2003). El Niño Tropical Pacific Ocean surface current and temperature evolution in 2002 and outlook for early 2003. Geophys. Res. Lett. 30(10) 1514, doi:10.1029/2003GL017096.

20. McPhaden, M.J. (2004). Evolution of the 2002/03 El Nino. Bull. Amer. Meteor. Soc. 85(5): 677-695.

21. Johnson, E.S., Lagerloef, G.S.E., Gunn, J.T. and Bonjean, F. (2002). Surface salinity advection in the tropical oceans compared with atmospheric freshwater forcing: A trial balance. J. Geophys. Res. 107(C12): 8014, doi:10.1029/2001JC001122.

22. Legeckis, R., Brown, C.W., Bonjean, F. and Johnson, E.S. (2004a). The influence of tropical instability waves on phytoplankton blooms in the wake of the Marquesas Islands during 1998 and on the currents observed during the drift of the Kon-Tiki in 1947. Geophys. Res. Lett. 31 L23307, doi:10.1029/2004GL021637.

23. Legeckis, R., Brown, C.W., Bonjean, F. and Johnson, E.S. (2004b). Satellites Reveal the Influence of Equatorial Currents and Tropical Instability Waves on the Drift of the Kon-Tiki in the Pacific. Oceanography 17(4): 166175 .

24. McPhaden, M.J., Cronin, M.F. and McClurg. D.C. (2008). Surface mixed layer temperature balance on seasonal time scales in the eastern tropical Pacific. J. Climate 21 3240-3260.

25. Helber, R.W., Weisberg, R.H., Bonjean, F., Johnson, E.S. and Lagerloef, G.S.E. (2007). Satellite-Derived Surface Current Divergence in Relation to Tropical Atlantic SST and Wind. J. Phys. Oceanogr. 37 1357-1375. 
26. Illig S., Dewitte, B., Ayoub, N., du Penhoat, Y., Reverdin, G., De Mey, P., Bonjean, F. and Lagerloef, G.S.E. (2004). Interannual long equatorial waves in the tropical Atlantic from a high-resolution ocean general circulation model experiment in 1981-2000. J. Geophys. Res 109 C02022, doi:10.1029/2003JC001771.

27. Foltz, G. R. and McPhaden, M.J. (2008). Seasonal mixed layer salinity balance of the tropical North Atlantic Ocean, J. Geophys. Res. 113 doi:10.1029/2007JC004178.

28. White, W.B., Cayan, D.R., Niiler, P.P., Moisan, J., Lagerloef, G.S.E., Bonjean, F. and Legler, D. (2005). The seasonal cycle of diabatic heat storage in the Pacific Ocean. Progress in Oceanography 64 1-29.

29. Cronin M. F., Fairall, C.W. and McPhaden, M.J. (2006). An assessment of buoy-derived and numerical weather prediction surface heat fluxes in the tropical Pacific, $J$. Geophys. Res., 111, C06038, doi:10.1029/2005JC003324

30. Kubota, M., Iwabe, N., Cronin, M.F. and Tomita, H. (2008). "Surface heat fluxes from the NCEP/NCAR and NCEP/DOE reanalyses at the KEO buoy site". $J$. Geophys. Res. 113 C02009, doi:10.1020/2007JC004338.

31. Johnson, E.S. and Proehl, J.A. (2004). Tropical Instability Wave Variability in the Pacific and Its Relation to Large-Scale Currents. J. Phys. Oceanogr. 342121 2147.

32. Farrar J.T. and Weller, R.A. (2006). Intraseasonal variability near $10^{\circ} \mathrm{N}$ in the eastern tropical Pacific Ocean. J. Geophys. Res. 111 C05015, doi:10.1029/2005JC002989.

33. Huang, B., Xue, Y. and Behringer, D.W. (2008). Impacts of Argo salinity in NCEP Global Ocean Data Assimilation System: The tropical Indian Ocean. $J$. Geophys. Res. 113 C08002, doi:10.1029/2007JC004388.

34. Balmaseda, M.A., Vidard, A. and Anderson, D.L.T. (2008). The ECMWF Ocean Analysis System: ORA-S3. Monthly Weather Review 136, 3018-3034.

35. Griffies, S. \& Co-Authors (2010). "Problems and Prospects in Large-Scale Ocean Circulation Models" in these proceedings (Vol. 2), doi:10.5270/OceanObs09.cwp.38

36. Maximenko, N., Niiler, P.P., Rio, M.-H., Melnichenko, O., Centurioni, L., Chambers, D., Zlotnicki, V. and Galperin, B. (2009). Mean dynamic topography of the ocean derived from satellite and drifting buoy data using three different techniques. J. Atmos. Oceanic Tech. 26(9), 1910-1919.

37. Uchida, H., and Imawaki, S. (2003). Eulerian mean surface velocity field derived by combining drifter and satellite altimeter data, Geophys. Res. Lett. 301229, doi:10.1029/2002GL016445.
38. Imawaki, S., Uchida, H., Ichikawa, K. and Ambe, D. (2003). Estimating the high-resolution mean sea-surface velocity field by combined use of altimeter and drifter data for geoid model improvement. Space Sci. Rev. 108 195-204.

39. Ambe, D., Imawaki, S., Uchida, H. and Ichikawa, K. (2004). Estimating the Kuroshio axis south of Japan using combination of satellite altimetry and drifting buoys. J. Oceanogr. 60, 375-382.

40. Ambe, D., Endoh, T., Hibiya, T. and Imawaki, S. (2009). Transition to the Large Meander path of the Kuroshio as observed by satellite altimetry. La Mer (in press).

41. Endoh, T. and Hibiya, T. (2001). Numerical simulation of the transient response of the Kuroshio leading to the large meander formation south of Japan, J. Geophys. Res., 106(C11), 26,8330-26,850.

42. Johnson, E.S., Bonjean, F., Lagerloef, G.S.E., Gunn, J.T. and Mitchum, G.T. (2007). Validation and Error Analysis of OSCAR Sea Surface Currents. Journal of Atmospheric and Oceanic Technology. 24 688-701.

43. Scott, R. \& Co-Authors (2010). "Satellite Altimetry and Key Observations: What We've Learned, and What's Possible with New Technologies" in these proceedings (Vol. 2), doi:10.5270/OceanObs09.cwp.76

44. Masumoto, Y. \& Co-Authors (2010). "Observing Systems in the Indian Ocean" in these proceedings (Vol. 2), doi:10.5270/OceanObs09.cwp.60

45. Gordon, A. \& Co-Authors (2010). "Interocean Exchange of Thermocline Water: Indonesian Throughflow; "Tassie" Leakage; Agulhas Leakage" in these proceedings (Vol. 2), doi:10.5270/OceanObs09.cwp.37

46. Lee, T. \& Co-Authors (2010). "Ocean State Estimation for Climate Research" in these proceedings (Vol. 2), doi:10.5270/OceanObs09.cwp.55

47. Stammer, D. \& Co-Authors (2010). "Ocean Information Provided Through Ensemble Ocean Syntheses" in these proceedings (Vol. 2), doi:10.5270/OceanObs09.cwp.85

48. Fairall, C.W., Bradley, E.F., Hare, J.E., Grachev, A.A. and Edson, J.B. (2003). Bulk parameterization of air-sea fluxes: Updates and verification for the COARE algorithm. J. Climate 16, 571-591.

49. Cronin, M. F., Fairall, C.W. and McPhaden, M.J. (2006). An assessment of buoy-derived and numerical weather prediction surface heat fluxes in the tropical Pacific. $J$. Geophys. Res. 111, C06038, doi:10.1029/2005JC003324

50. Send, U. \& Co-Authors (2010). "A Global Boundary Current Circulation Observing Network" in these proceedings (Vol. 2), doi:10.5270/OceanObs09.cwp.78 
51. Cronin, M. \& Co-Authors (2010). "Monitoring Ocean Atmosphere Interactions in Western Boundary Current Extensions" in these proceedings (Vol. 2), doi:10.5270/OceanObs09.cwp.20

52. Chelton, D.B., Schlax, M.G., Freilich, M.H. and Milliff, R.F. (2004). Satellite Measurements Reveal Persistent Small-Scale Features in Ocean Winds. Science 303(5660), 978 - 983, doi:10.1126/science.1091901.

53. Centurioni, L. R., Ohlmann, J.C. and Niiler, P.P. (2008). Permanent Meanders in the California Current System. J. Phys. Oceanogr. 38(8), 1690-1710.

54. Fu, L. \& Co-Authors (2010). "The Surface Water and Ocean Topography (SWOT) Mission" in these proceedings (Vol. 2), doi:10.5270/OceanObs09.cwp.33

55. Wunsch, C. and Ferrari, R. (2004). Vertical mixing, energy and the general circulation of the oceans, Ann. Rev. Fluid Mech. 36 281-314, doi:10.1146/annurev.fluid.36.050802.122121.

56. MacKinnon, J. \& Co-Authors (2010). "Using Global Arrays to Investigate Internal Waves and Mixing" in these proceedings (Vol. 2), doi:10.5270/OceanObs09.cwp.58

57. Chaigneau, A., Pizarro, O. and Rojas, W. (2008). Global climatology of near-inertial current characteristics from Lagrangian observations. Geophys. Res. Letters, 35, L13603, doi:10.1029/2008GL034060.

58. Niiler, P.P., Davis, R.E. and White, H.J. (1987). Waterfollowing characteristics of a mixed layer drifter. DeepSea Research Part a-Oceanographic Research Papers 34(11): 1867-1881.

59. Niiler, P.P. and Paduan, J.D. (1995). Wind-driven motions in the Northeast Pacific as measured by Lagrangian drifters. J. Phys. Oceanogr. 25(11): 2819-2830.

60. Pluedemann, A.J., Smith, J.A., Farmer, D.M., Weller, R.A., Crawford, W.R., Pinkel, R., Vagle S. and Gnanadesikan, A. (1996). Structure and variability of Langmuir circulation during the Surface Waves Processes Program. J. Geophys. Res. 101(C2) 35253543.

61. Cipollini, P. \& Co-Authors (2010). "The Role of Altimetry in Coastal Observing Systems" in these proceedings (Vol. 2), doi:10.5270/OceanObs09.cwp.16

62. Lagerloef, G. \& Co-Authors (2010). "Resolving the Global Surface Salinity Field and Variations by Blending Satellite and In Situ Observations" in these proceedings (Vol. 2), doi:10.5270/OceanObs09.cwp.51

63. Nakano, Y. (2008). Developing a small drifting buoy system with sea surface CO2 sensor, ARGOS forum, 67 , 8-9 (http://www.argossystem.org/documents/publications/newsletter/anl_67.pd f).

64. Maximenko, N. A., Melnichenko, O.V., Niiler, P.P. and Sasaki, H. (2008). Stationary mesoscale jet-like features in the ocean, Geophys. Res. Lett. 35 L08603, doi:10.1029/2008GL033267.
65. Stammer, D. (1997). Global characteristics of ocean variability estimated from regional TOPEX/Poseidon altimeter measurements. J. Phys. Oceanogr. $271743-$ 1769. 